\title{
COLEGIATA DE PRAVIA: MAGNIFICENCIA DE LAS ALHAJAS DE PROCEDENCIA VIRREINAL PERUANA*
}

\author{
POR \\ YAYOI KAWAMURA \\ Universidad de Oviedo
}

La Colegiata de Pravia, Asturias, fue fundada en 1715 por Fernando Ignacio Arango Queipo, tras su estancia en Charcas, Virreinato del Perú, acompañando a su tío Juan Queipo de Llano, arzobispo de Charcas. El artículo analiza su dotación artística, en especial una serie de objetos litúrgicos de oro y plata de procedencia peruana. A pesar de la desgraciada desaparición de la mayoría de ellos, se conservan dos piezas de oro y piedras preciosas hechas en Perú y datables en la primera década del siglo xviII, que constituyen un valioso punto de referencia para el estudio de la platería del Virreinato peruano.

Palabras clave: Pravia; Fernando Ignacio de Arango; Juan Queipo de Llano; platería; Charcas; Virreinato del Perú.

The Collegiate Church of Pravia, Asturias, was founded in 1715 by Fernando Ignacio Arango Quiepo, following his stay in Charcas, Viceroyship of Peru, accompanying his uncle Juan Quiepo de Llano, Archbishop of Charcas. In this article the author analyzes the artistic endowment of the Collegiate Church, particularly a series of gold and silver liturgical objects from Peru. In spite of the unfortunate disappearance of the majority of them, two gold objects decorated with precious stones made in Peru dating from the first decade of the $18^{\text {th }}$ century have survived. They constuitute a valuable point of reference for the study of silversmith work in the Viceroyship of Peru.

Key words: Pravia; Fernando Ignacio de Arango; Juan Queipo de Llano; silversmith work; Charcas; Viceroyship of Peru.

\section{La fundación de la colegiata}

La colegiata de la villa de Pravia fue fundada en 1715 por Fernando Ignacio Arango y Queipo (Pravia, Asturias, 17 de marzo de 1673 - Tuy, 17 de marzo de 1745), bajo la advocación del Santísimo Sacramento y de Nuestra Señora del Valle ${ }^{1}$. El fundador, por línea paterna,

* Para la realización de este trabajo he podido contar con la inestimable colaboración de varias personas, en especial de José Antonio Martínez González, autor de Historia de la Colegiata de Pravia (Solar Ediciones, 1997), a quien manifiesto mi gratitud.

1 Archivo parroquial de Pravia, Libro de bautizados, casados y difuntos (1626-1671), tomo I, f. 143v. Bances, Juan, «Pravia», en Bellmunt y Traver, O. y Canellas y Secades, F., Asturias, Gijón, Silverio Cañada, tomo I, 1895, pp. 315-329. 
pertenece a la familia Arango, hidalgo, y por la materna, al conocido linaje de Queipo de Llano. El mayorazgo de la familia recaía en su hermano Bartolomé Arango Miranda. Mientras tanto, Fernando Ignacio eligió la carrera eclesiástica; tras estudiar el Derecho Canónico en la Universidad de Oviedo, se trasladó a La Plata en 1694, coincidiendo con la elevación de su tío, Juan Queipo de Llano, al arzobispado de Charcas, donde asumió cargos de importancia. Al fallecer Juan Queipo de Llano en 1708, su sobrino abandonó La Plata regresando a España, al parecer con gran fortuna.

Quizá utilizando hábilmente dicha capacidad económica, y, como no, apoyado por el linaje de Queipo de Llano, recibió los favores de Felipe V. Consiguió ser caballero de la Orden de Santiago en $1709^{2}$. En 1712 formaba parte del Consejo de Indias como oidor togado ${ }^{3}$, y en 1715 fue nombrado abad perpetuo del Real Convento de San Isidoro de León ${ }^{4}$. Unos meses antes de su ingreso en el Real Convento de San Isidoro, Fernando Ignacio tomó la decisión de fundar una colegiata y obra pía en la villa de Pravia. Cinco años más tarde se promovió a la sede episcopal de Tuy, ocupando la mitra desde marzo de 1721 hasta marzo de 1745 , fecha de su fallecimiento ${ }^{5}$.

La fundación se concreta mediante las Constituciones, rubricadas en León ante el escribano Alonso Álvarez de Hevia el uno de junio de $1715^{6}$, y publicadas en impreso en Madrid tres años después ${ }^{7}$. Dicha fundación consiste en construir una iglesia con categoría de colegiata y vice-parroquia, con la capellanía mayor y otras ocho capellanías. Por otro lado, funda una escuela para la enseñanza de los niños, y un centro de estudios de gramática. Asimismo, como obra pía destina 3.000 reales anuales a modo de dote para las niñas pobres de familias hidalgas que tomen el estado religioso o matrimonial. Para el conjunto de esta fundación se destinan 100.000 ducados basados en censos y foros de fincas y tierras.

Al mismo tiempo de redactar las constituciones de la fundación, ante el mismo escribano, Fernando Ignacio Arango testa su última voluntad ${ }^{8}$. El capítulo que más nos interesa del testamento es el referido a sus bienes. Declara haber realizado un inventario dos meses antes en Madrid ante el escribano Carlos de Carriola y con la presencia de un canónigo de San Isidoro de León, poderhabiente del prior, y un agente general de Su Majestad y de su patronato, el cual duró trece días, por lo que podemos suponer el gran volumen de sus bienes y el importe que pudo alcanzar la suma ${ }^{9}$. El testamento habla de los frutos y rentas de la hacienda y censos que tiene en Asturias, y también alude a sus posesiones en América: fincas y capellanías en Potosí y en La Plata. Asimismo, se refiere, una a una, a las alhajas de oro y plata depositadas en la casa de su hermano Bartolomé en Pravia.

\footnotetext{
Banzes y Valdés, Antonio Juan de, «Noticias históricas del concejo de Pravia», Boletín de la Real Académia de la Historia, Madrid, t. LVIII, 1911, p. 354. Cadenas y Vicent, V. de, Caballeros de la Orden de Santiago. Siglo XVIII, Madrid, tomo II, 1977, pp. 6-7. Santiso, A., Los obispos de Tui y sus armas, Tuy, 1994, p. 108. Martínez González, op. cit., p. 11.

${ }^{2}$ Cadenas y Vicent, op. cit., n. ${ }^{\circ} 367$, año 1709, sig. 521.

${ }^{3}$ Santiso, A., op. cit. En la inscripción al pie de su retrato conservado en el Palacio de Moutas, Pravia, se relacionan todos los cargos que tuvo hasta ser obispo de Tuy; el texto dice: «y de edad de 39 años, del Consejo de Su Magestad su oidor togado en el Real Supremo de las Indias».

${ }^{4}$ Archivo de San Isidoro de León, E/20-19.

5 Ávila y la Cueva, F., Historia civil y eclesiástica de la ciudad de Tuy y obispado, Tuy, vol. IV, 1995, pp. 318-322 [edición facsimilar de m.s., Tuy, 1852]. Rodríguez y García, F., Ensayo para una galería de asturianos ilustres, Cebú, tomo I, 1888, pp. 22-23; tomo III, 1891, pp. 797-798.

${ }^{6}$ AHPL, P. N. de León, C. 453, Sig. 711, ff. 304-350, escribano Alonso Álvarez de Hevia. Silvia Fernández, en su memoria de licenciatura Los retablos de la cabecera de la colegiata de Pravia (Universidad de Oviedo, 1972, inédita), hace referencia a dicho documento, sin aportar ningún análisis.

7 Impreso por Diego Martínez Abad, en Madrid, 1718. Martínez González, op. cit., pp. 201-275.

8 AHPL, P. N. de León, C. 453, Sig. 711, ff. 351-378.

9 No he encontrado en los archivos de Madrid este inventario, que se inició el 28 de marzo y finalizó el 9 de abril de 1715 .
}

$A E A, \mathrm{LXXVII}, 2004,307$, pp. 281 a 290 
Antes de concluir el testamento, insiste en su deseo y preferencia por levantar la iglesia vice-parroquial en Pravia que debe «alhajarse de retablos, cálices, ornamentos santos, lámparas, campanas, sillas de coro, los demás necesarios». Parece claro que el futuro abad quería dar cuenta de sus propiedades antes de su ingreso en la comunidad agustina con la intención de no llevarlas al convento, y determina claramente el uso que hay que dar a sus bienes y dinero: fundar una colegiata y obras pías en su villa natal, Pravia.

Como apunta V. de la Madrid, la iglesia estaba en la última fase de construcción en 1727, enlosándose el suelo, y la obra se finalizó en $1728{ }^{10}$. El interior de la iglesia estaba completándose, al mismo tiempo que la obra de la fábrica, con los retablos e imágenes de las mejores expresiones de la forma barroca, como indica G. Ramallo ${ }^{11}$.

Aparte de los retablos e imágenes, el «alhajar la iglesia» suponía la dotación de objetos de plata, ornamentos litúrgicos, muebles, órgano y campanas. La aportación de los objetos de culto más importantes debió de realizarse antes de la fecha de la consagración celebrada por el fundador, siendo ya obispo de Tuy, el 13 de julio de 1727, y, en una segunda fase, con motivo de la consagración de los altares laterales en $1729^{12}$.

\section{Alhajas de oro y plata}

Nos centramos en las alhajas de oro y plata con las que el fundador dotó a la colegiata. Coincidiendo con el nombramiento de un nuevo capellán, Manuel González del Rosal, en 1749, se realizó un inventario de las alhajas del templo, que constituye la primera relación completa conservada de las mismas ${ }^{13}$. El segundo documento de las mismas características tiene fecha de 1798 al ser nombrado Manuel Pérez Rodiles San Miguel como nuevo sacristán de la colegiata ${ }^{14}$. En estos inventarios se citan varias alhajas de plata, y es razonable suponer la presencia de la plata virreinal peruana en ellas.

En el testamento antes mencionado de 1715 , se enumeran los objetos de metal noble de su propiedad que se encontraban guardados en un cajón claveteado en Pravia ${ }^{15}$; además declara que esas alhajas fueron expuestas por su hermano ante el escribano de Pravia, que supusieron un valor de 3.220 pesos escudos de «plata vieja» ${ }^{16}$, y que eran las siguientes: un viril de plata sobredorada, un cáliz de oro con esmalte, otro cáliz de oro para el Jueves Santo, un copón y dos cálices de plata sobredorada, una custodia de plata con columnas salomónicas y unas planchas que se entienden sacras. En el testamento no se hace referencia a su peso ni valor individual. En la relación de las alhajas que se realizó en 1749, en la que se aprecia un considerable aumento de objetos de plata, se cita el peso de cada una de ellas.

\footnotetext{
${ }^{10}$ Madrid Álvarez, V. de la, El arquitecto barroco Francisco de la Riva Ladrón de Guevarra, Gijón, Trea, 1998 , p. 105.

11 Ramallo Asensio, G., "Aportaciones a la obra de Juan Alonso Villabrille y Ron. Escultor asturiano», Archivo Español de Arte, Madrid, CSIC, n. ${ }^{\circ} 214,1981$, pp. 211-220; Escultura barroca en Asturias, Oviedo, IDEA, 1985, pp. 397 y 443446.

12 Martínez González, op. cit., pp. 34-40.

13 Archivo particular, Pravia; documento fechado el 21 de octubre de 1749 ante el escribano Martín del Bao, de la villa de Pravia: Entrega de las alhajas de la iglesia viceparroquial de Pravia al nuevo sacristán Manuel González del Rosal. Martínez González, op. cit., pp. 57-64.

${ }^{14}$ Archivo particular, Pravia; documento fechado el 24 de marzo de 1794 ante el escribano Juan López Gutiérrez, de la villa de Pravia: Entrega de las alhajas de la iglesia viceparroquial de Pravia al nuevo sacristán Manuel Pérez Rodiles San Miguel.

${ }^{15}$ En la colegiata de Pravia, actualmente se encuentra un arca de madera $(51 \mathrm{~cm} . \times 132 \mathrm{~cm} . \times 60 \mathrm{~cm}$. $)$ de tapa plana con tres cerraduras, y dos asas en los laterales. La pieza está totalmente forrada con numerosas bandas de hierro forjado de anchura entre 4 y $8 \mathrm{~cm}$., en sentido vertical y horizontal, convirtiéndose el arca en una auténtica caja fuerte, que puede corresponder a dicho «cajón claveteado».

${ }^{16}$ Anteriormente al inventario de Madrid, se hizo la presentación de las alhajas en Pravia ante el escribano Francisco Cuervo el 29 de enero de 1715. Desgraciadamente este documento no se conserva.
}

$A E A$, LXXVII, 2004, 307, pp. 281 a 290 
El análisis comparativo de estas dos relaciones nos proporciona la información respecto al aspecto y peso de cada pieza referida en 1715, llegando a la conclusión de que esas muestras de plata declaradas en 1715 son procedentes de los talleres de Charcas, bien de La Plata o de Potosí, y que otras piezas que se incorporan después son probablemente adquiridas en España. Transcribimos a continuación la relación de las alhajas de procedencia virreinal como se describen en el inventario de 1749: «un viril de una bara de alto de plata sobredorada y esmaltado con su peana ancha de lo mismo con quatro ebangelistas y dibersas piezas en el pedestal asta los rayos del sol con su media luna de oro, que todo ello pesa diez y siete libras castellanas y un quarterón» $(83,59 \mathrm{~cm}$ de alto, 7,935 g.); «dos cálices de plata sobredorada ${ }^{17}$ de hechura ochabada con sus esmaltes en pie, coluna y copa, que pesan quatro libras castellanas con sus patenas sobredoradas» $(1,840$ g.); «un copón en forma de cáliz depósito de Santíssimo Sacramento de plata sobredorada, que pesa dos libras castellanas» (920 g.); «un cáliz con patena y copa de oro y el pie y coluna de plata sobredorada, y pesa veinte y siete onzas poco más o menos» (776 g.); «un cáliz de plata sobredorada con su patena de lo mismo, que pesa veinte y una onzas» (630 g.); «un templo salomónico para el depósito del Juebes Santo, todo de plata maziza de más de media bara de alto y media bara de ancho, con sus puertas clavadas, cadenas y colunas, que pesa diez y nuebe libras y media» $(42 \mathrm{~cm}$. de alto, $42 \mathrm{~cm}$. de ancho, 8,740 g.); «una sacra entera con sus colunas y guarnizión, pies y remates; más otra con tres ojas en que se contienen las Sacras, Credo, Gloria y más oraziones sin ninguna guarnizión; dos ojas con el Evangelio de San Juan cada una, y otras dos ojas con el Salmo cada una, todas las letras ronpidas en las mismas ojas así de las sacras como de los Evangelios y Salmo, que está todo por armar, y pesan catorze libras castellanas y quarterón, digo menos quarterón» $(6,325 \mathrm{~g}$.).

Las obras que más nos llaman la atención son el «viril» y el «templo salomónico». Ambas piezas están destinadas a contener la sagrada forma; una para la festividad del Corpus Christi y la otra para el Jueves Santo. La estrecha relación con la Eucaristía de estos objetos de más peso y valor revela la devoción del fundador a dicho culto, sin olvidar, además, que la nueva iglesia se funda bajo advocación del Santísimo Sacramento. El viril tiene casi $85 \mathrm{~cm}$ de alto y pesa casi $8 \mathrm{~kg}$. Seguramente se trata de una custodia que se colocaba en andas para la procesión. Según la descripción, el viril está acompañado de las imágenes de los cuatro evangelistas, probablemente piezas de fundición de plata cinceladas de considerable tamaño, y otros elementos ornamentales esmaltados en abundancia, quizá flores, follajes y tarjas, como corresponde a la platería altoperuana de aquel momento. Podemos imaginar una obra similar al modelo de custodia muy difundido en el Virreinato del Perú fabricado en los talleres de Lima, Cuzco, Trujillo, La Plata y Potosí ${ }^{18}$, con un gran desarrollo del sol, pero con la añadidura de las figuras de los evangelistas en el basamento. El «templo salomónico» es una custodia fija que pesa cerca de $9 \mathrm{~kg}$. con estructura de templete casi cúbico, $42 \mathrm{~cm}$ de ancho y de alto, compuesto con columnas salomónicas. Debió de estar destinado a acoger uno de los cálices de oro, depósito del Jueves Santo, señalado en el testamento.

La aparición de la columna salomónica en la platería americana es frecuente. Por un lado, un templete de plata puede ser réplica del altar o retablo de los Reyes muy difundido en Hispanoamérica, donde se utiliza el orden salomónico para manifestar de modo patente el regio

\footnotetext{
${ }_{17}$ Estas piezas de oro, una de las cuales aún se conserva, en aquel momento fueron consideradas erróneamente de plata sobredorada.

${ }^{18}$ Heredia Moreno, M. C., Orbe Sivatte, M. y Orbe Sivatte, A., Arte Hispanoamericano en Navarra, Pamplona, Gobierno de Navarra, 1992, p. 169, notas 6 y 7. Esteras Martín, C., «El oro y la plata americano, del valor económico a la expresión artística», El oro y la plata de las Indias en la época de los Austrias, catálogo de la exposición, Madrid, Fundación ICO, 1999, pp. 393-423, ord. 250.
}

AEA, LXXVII, 2004, 307, pp. 281 a 290 
patronato sobre la Iglesia en Indias. Por otro lado, observamos la gran difusión de las columnas salomónicas en el arte y la arquitectura del arzobispado de Charcas ${ }^{19}$.

Aparte de estas dos obras de llamativa presencia y peso, otra pieza de plata de considerable peso es el conjunto de sacras que pesa más de $6 \mathrm{~kg}$. También la presencia de dos cálices de oro ornamentados habla por sí sola de la extraordinaria calidad de las alhajas.

La mayoría de estas piezas se conservaron en la iglesia praviana hasta septiembre de 1936. En la relación de los objetos desaparecidos durante los sucesos de aquel mes figuran «un gran viril precioso de la época de la Colegiata, de plata sobredorada con apliques alegóricos y esmaltes, de una vara de alto» $\mathrm{y}$ «un sagrario, estilo colonial, de plata vieja repujada, que se usaba como custodia en el monumento del Jueves Santo» ${ }^{20}$; la descripción hace referencia claramente a dos de las obras más importantes que Fernando Ignacio Arango trajo de Charcas. A pesar del desgraciado hecho, uno de los cálices de oro aún se conserva, como único testigo del esplendor litúrgico en materia de platería, con el que el fundador dotó a la colegiata.

El cáliz, hecho de oro y muy ornamentado, es uno de los dos que aparecen citados en el testamento de 1715, y por la altura normal que posee, no se trata del destinado para el uso del Jueves Santo, sino del otro (Figs. 1 y 2). En el inventario de 1749 corresponde a uno de los dos cálices de hechura ochavada. La muestra mide $20,2 \mathrm{~cm}$. de altura, $13 \mathrm{~cm}$. de diámetro en el pie y $8,2 \mathrm{~cm}$. en la boca, y pesa $1.000 \mathrm{~g}^{21}$.

La pieza presenta una estructura octogonal; el borde del pie es lobulado con sección cóncava y, a continuación, se desarrollan tres cuerpos escalonados octogonales acompañados de un cuerpo bocelado entre ellos. El astil, que mantiene el ochavado, se inicia con una forma bulbosa, y, tras cuatro platos aristados y salientes de distintos tamaños, presenta el nudo central, que es una gruesa moldura bocelada octogonal acompañada de un tramo de astil de mayor diámetro. El astil termina con tres platos octogonales de diferentes tamaños. La copa presenta una suave conicidad abriéndose más en la boca de modo campaniforme. La subcopa, que ocupa un tercio de la altura de la copa, muestra una forma muy diferenciada de ella. Mantiene la estructura octogonal y es una combinación de un grueso bocel y un plato saliente con un estrechamiento del cuerpo en medio.

Sobre esta estructura de diseño geométrico y perfil quebrado, de raigambre manierista, se aprecian numerosos sobrepuestos de piedras y esmaltes. Las gemas, de talla tosca, están engastadas y colocadas en hilera rodeadas de finas piezas de esmaltado pictórico, en forma de pétalo, blancas con rayas verdes. En cada uno de los ocho lóbulos del pie se encuentra un sobrepuesto de este tipo con una pareja de diamantes; en el primer escalón octogonal, cuatro sobrepuestos de cuatro diamantes y otros cuatro de tres granates alternativamente; en el segundo escalón, dos sobrepuestos de una esmeralda ovalada, dos de un peridoto circular y otros cuatro de una combinación de un posible vidrio verde triangular y un rubí; y en el último escalón, alternancia de un rubí y un diamante.

El nudo inferior octogonal lleva el mismo aplique con tres diamantes de modo vertical en cuatro caras, y a continuación, otro de dos esmeraldas en las otras cuatro caras. La zona del nudo central, también octogonal, está ricamente ornamentada: en la parte gruesa inmediatamente inferior al nudo se encuentran cuatro sobrepuestos, cada uno con un diamante, dejando al-

\footnotetext{
19 En los sagrarios de la catedral y de la Merced de Potosí se contempla una abrumadora presencia de columnas salomónicas ricamente decoradas con follajes, flores y frutas. Un «carro» eucarístico de plata que se fabricó en 1737 en Potosí se componía de orden salomónico. Chacón Torres, M., Arte virreinal en Potosí. Fuentes para su historia, Sevilla, Escuela de Estudios Hispano-Americanos de Sevilla, 1973. Ribera, A. L. y Schenone, H., Platería sudamericana de los siglos xvIIxx, Munich, Bayerische Nationalmuseum, 1981, pp. 40-47.

${ }^{20}$ Hoja parroquial del arciprestazgo de Pravia, Pravia, n. ${ }^{\circ} 1233,7$ de septiembre de 1937.

${ }^{21}$ El cáliz se encuentra en la actualidad en el Museo de la Iglesia, de la archidiócesis de Oviedo, sito en el claustro alto de la catedral de Oviedo. Vv. Aa., Catálogo del Museo de la Iglesia, ord. O79, Oviedo (en prensa).
} 

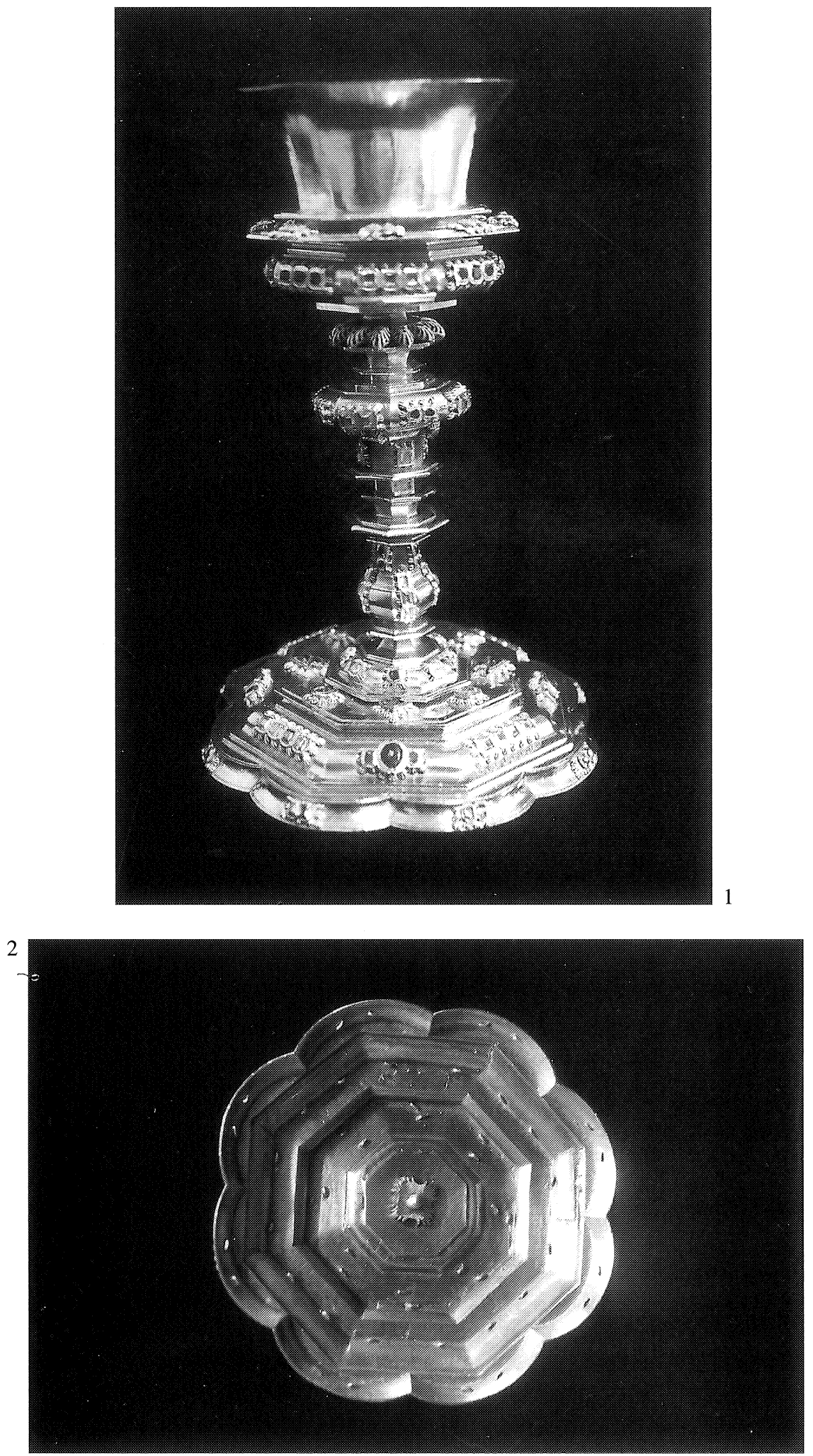

Fig. 1. Cáliz de oro, piedras y esmalte; procedente de Charcas, primeros años del siglo XVIII. Fig. 2. Detalle del mismo: reverso del pie.

AEA, LXXVII, 2004, 307, pp. 281 a 290 
ternativamente cuatro caras lisas; en la zona inferior del mismo nudo bocelado, el mismo tipo de aplique se repite cuatro veces con una esmeralda; y en la parte más saliente del nudo se aprecia la alternancia de uno con dos rubíes y otro de dos diamantes, que cubren las ocho caras. El plato saliente situado en el cuello está acompañado de doce pétalos esmaltados de mayores dimensiones.

El cuerpo grueso de la subcopa está decorado de modo igual que el nudo central: alternancia de apliques de tres rubíes y de cinco diamantes. El plato octogonal saliente que marca el final de la subcopa está acompañado de ocho sobrepuestos, cada uno de dos diamantes ${ }^{22}$. Estas piezas de adorno están sujetas sobre la estructura del cáliz con la ayuda de dos ganchos que atraviesan la chapa de oro.

La tosquedad de talla de las piedras, sobre todo del diamante, habla del poco adiestramiento del artífice en esta labor. La aplicación de granates y peridoto, e incluso de vidrio, en tamaño relativamente grande indica la dificultad de reunir un alto número de rubíes y esmeraldas de esas dimensiones.

La estructura octogonal es una de las formas preferidas en la platería novohispana del siglo xviII avanzado. La platería de la Capitanía General de Guatemala también se asocia con la forma octogonal, especialmente en el tratamiento de la peana o pie, como podemos apreciar en el conjunto de la parroquia de Lesaca ${ }^{23}$. También es común observar en los cálices guatemaltecos un astil compuesto de varios cuerpos o nudos bulbosos, y una subcopa muy diferenciada. Sirve de ejemplo los cálices de Lesasca y de Santesteban, sin embargo, esas obras son del siglo XVIII avanzado, de estética plenamente barroca ${ }^{24}$. Por otro lado, la repetición de los platos aristados y salientes en el astil es característica de los cálices peruanos del último cuarto del XVII y el primero del siguiente ${ }^{25}$, pero esas muestras suelen ser lisas. Una estructura similar a la del cáliz praviano, salvo el carácter octogonal, la encontramos en los cálices peruanos de San Saturnino de Pamplona y de Mendigorría ${ }^{26}$, y también de la Merced de Quito ${ }^{27}$ y de Tarifa ${ }^{28}$. En cuanto al aspecto ornamental, la platería peruana ofrece numerosas muestras decoradas con esmalte, aspecto muy frecuente en las custodias ostensorios ${ }^{29}$. El uso de piedras engastadas también está muy difundido en el Virreinato peruano, como podemos apreciarlo en el manto metálico de la imagen de Nuestra Señora de Guadalupe, en la catedral de Sucre (La Plata) ${ }^{30}$ y también en el peto de la Virgen conservado en Characato, Arequipa ${ }^{31}$. El ejemplar nuestro cuenta con la presencia de pedrería de variado color y esmalte, ofreciendo una riqueza y fastuosidad poco frecuente. A pesar de presentar un cuerpo tan geométrico y de superficies lisas, reminiscencia del estilo del siglo xvII, la abundante ornamentación superpuesta enmascara a la primera vista esa característica estructural.

${ }^{22} \mathrm{El}$ análisis de las gemas se basa en un examen ocular del joyero Carlos Álvarez de Benito, inestimable colaborador de mi trabajo.

${ }^{23}$ Heredia Moreno, Orbe Sivatte y Orbe Sivatte, op. cit., pp. 135-141.

${ }^{24}$ Ibidem., pp. 135-137 y 145.

${ }^{25}$ Heredia Moreno, M. C., «Cálices peruanos en Navarra», Principe de Viana, Pamplona, n. ${ }^{\circ}$ 160-161, 1980, pp. 561575. Heredia Moreno, Orbe Sivatte y Orbe Sivatte, op. cit., pp. 157-164.

${ }^{26}$ Heredia Moreno, M. C., «Cálices peruanos en Navarra», op. cit.

${ }^{27}$ Herrarez Ortega, M. V. y Paniagua Pérez, J., «Hacia una tipología de los cálices quiteños. Los cálices de la Merced de Quito», Cuadernos de Arte Colonial, Madrid, Museo de América, 1988, n. ${ }^{\circ}$, pp. 107-120, ord. 6.

${ }^{28}$ Esteras Martín, C., «Nuevas aportaciones a la historia de la platería andaluz-americana», III Jornadas de Andalucía y América, Sevilla, 1985.

${ }^{29}$ Existen numerosos ejemplares conocidos; como referencia cito los siguientes estudios: Esteras Martín, C., Platería Hispanoamericana. Siglos XVI-XIX, Badajoz; «El oro y la plata americano ...», op. cit. Heredia Moreno, M. C., «Problemática de la orfebrería peruana en España. Ensayo de una tipología», Príncipe de Viana, Pamplona, n.. ${ }^{\circ} 175,1985$, pp. 339358. Heredia Moreno, Orbe Sivatte y Orbe Sivatte, op. cit., pp.165-172.

30 Arbeteta, L., «La joyería: manifestación suntuaria de los dos mundos», en El oro y la plata de las Indias, op. cit., pp. 425-449.

${ }^{31}$ Esteras Martín, C., Arequipa y el arte de la platería. Siglos XVI-XX, Madrid, Tuero, 1993, pp. 160-161. 
Para ampliar nuestro conocimiento sobre la orfebrería altoperuana del momento, tenemos otra pieza de oro y gemas de la misma procedencia chuquisaqueña en Asturias. Se trata de un relicario para la Santa Espina donado por el arzobispo de Charcas, Juan Queipo de Llano Valdés, tío de Fernando Ignacio, a su pueblo natal, Santianes (Tineo, Asturias). Según Méndez García la donación data de $1707^{32}$; probablemente lo trajo su sobrino en nombre del arzobispo. Igual que el cáliz de Pravia, es de oro y decorado de modo similar, y siendo una pieza diminuta la elaboración es más fina y primorosa (Figs. 3 y 4 ).

El relicario, en forma de recipiente ovalado hecho de cristal de roca, con su pie y tapa de oro adornados con piedras preciosas, mide $7 \mathrm{~cm}$. de altura, $4 \mathrm{~cm}$. de diámetro máximo, $3,5 \mathrm{~cm}$. de diámetro del pie y de la tapa. Está, a su vez, guardado dentro de otro estuche de plata sobredorada, que mide $11,4 \mathrm{~cm}$. de altura, $5 \mathrm{~cm}$. de diámetro máximo, $3,5 \mathrm{~cm}$. de diámetro del pie y $5 \mathrm{~cm}$. de diámetro de la tapa. Este doble envoltorio de la reliquia se custodia dentro de un pequeño cofre hecho de carey con cerradura, cantoneras y patas de plata, pieza muy característica de Nueva España en la segunda mitad del siglo xviI, que mide $12 \mathrm{~cm}$. de altura, 15,4 $\mathrm{cm}$. ancho y $7 \mathrm{~cm}$. de fondo.

La calidad de trabajo del relicario es sumamente alta. El pie circular presenta un borde finamente dentado; los diminutos dientes están decorados con esmalte en negro. Ocho piezas cuadradas de topacio de talla fina adornan el pie; entre una piedra y otra se configura un motivo calado en forma de arco tratado con esmalte negro. El pie termina en una arandela dentada, cuyos dientes alternativamente están esmaltados en negro. El pie sujeta un cuerpo ovalado hecho de cristal de roca de considerable espesor. La parte superior está adornada con dieciséis gallones cóncavos de talla profunda, y la parte central está acompañada de cuatro motivos de roleo vegetal grabados. La tapa muestra un borde dentado esmaltado acompañado de veinte esmeraldas cuadradas, y la parte central cónica está calada y adornada con otras ocho esmeraldas, cuatro cuadradas y otras cuatro triangulares colocadas alternativamente. Debió de existir otra piedra en el remate, actualmente perdida, dejando el asiento de engaste vacío. En el interior se sitúa un capullo de ocho pétalos que sujeta en medio la reliquia.

El modelo del relicario es singular y no conocemos otro ejemplar comparable. Las características que muestra el relicario atestiguan el alto nivel de trabajo de los plateros de oro, probablemente de La Plata o de Potosí, adiestrados para elaborar artículos de lujo y refinamiento, ya que esa era la exigencia de la clientela.

Sobre la donación de estas dos muestras por Fernando Ignacio de Arango y por Juan Queipo de Llano no existe duda, y tampoco sobre su procedencia altoperuana, de La Plata o de Potosí. La fecha de producción podemos asegurarla en los primeros años del siglo XviII, antes de 1708. Por lo tanto, estamos ante dos ejemplares de singular valor con la procedencia y datación claramente identificadas. Como es sabido, la práctica de marcaje llevada con poco rigor en la plata del Virreinato peruano dificulta el estudio de la tipología de las obras allí producidas. Por lo que, estas piezas constituyen un valioso punto de referencia para el estudio de la platería de la archidiócesis de Charcas.

Al comparar la relación de los objetos de plata del testamento de 1715 y el inventario de los mismos realizados en 1749 , se aprecia un incremento, como se ha indicado antes. Son alhajas de plata imprescindibles para el templo, que probablemente se entregaron para la consagración de la colegiata. Se trata de una cruz procesional (3,500 g.); una custodia ostentorio sobredorada para la exposición del Jueves Santo (460 g.), un copón para el sagrario, una lám-

\footnotetext{
${ }^{32}$ Méndez García, Z., Los siglos de oro de Tuña, Luarca, 1932, p. 106. El autor llegó a leer la escritura de donación y confirma su conservación en el oratorio del palacio de Santianes en 1932. En la actualidad la pieza se conserva en una colección particular de Asturias. La construcción de la capilla en dicho palacio, fechada en 1713 según una inscripción en la viga, pudo ser motivada por la llegada de tan preciada reliquia.
}

AEA, LXXVII, 2004, 307, pp. 281 a 290 


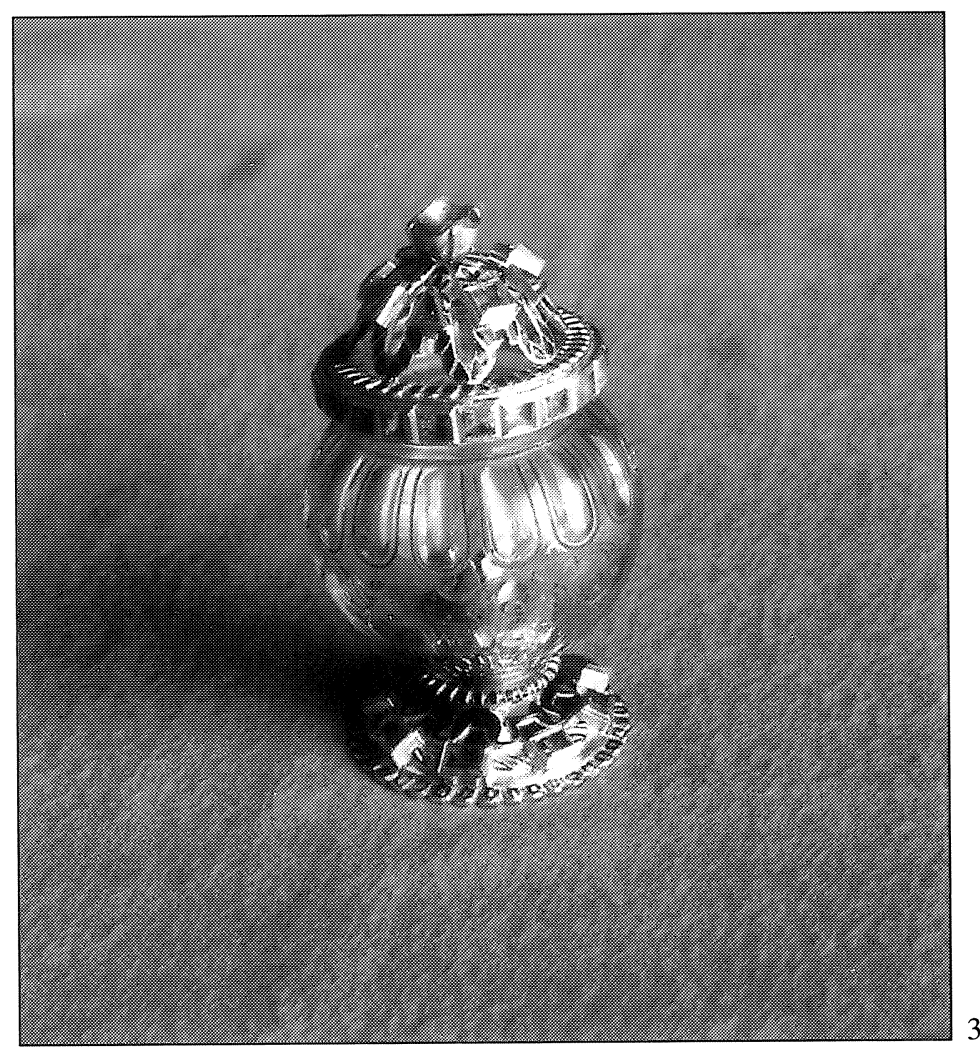

4

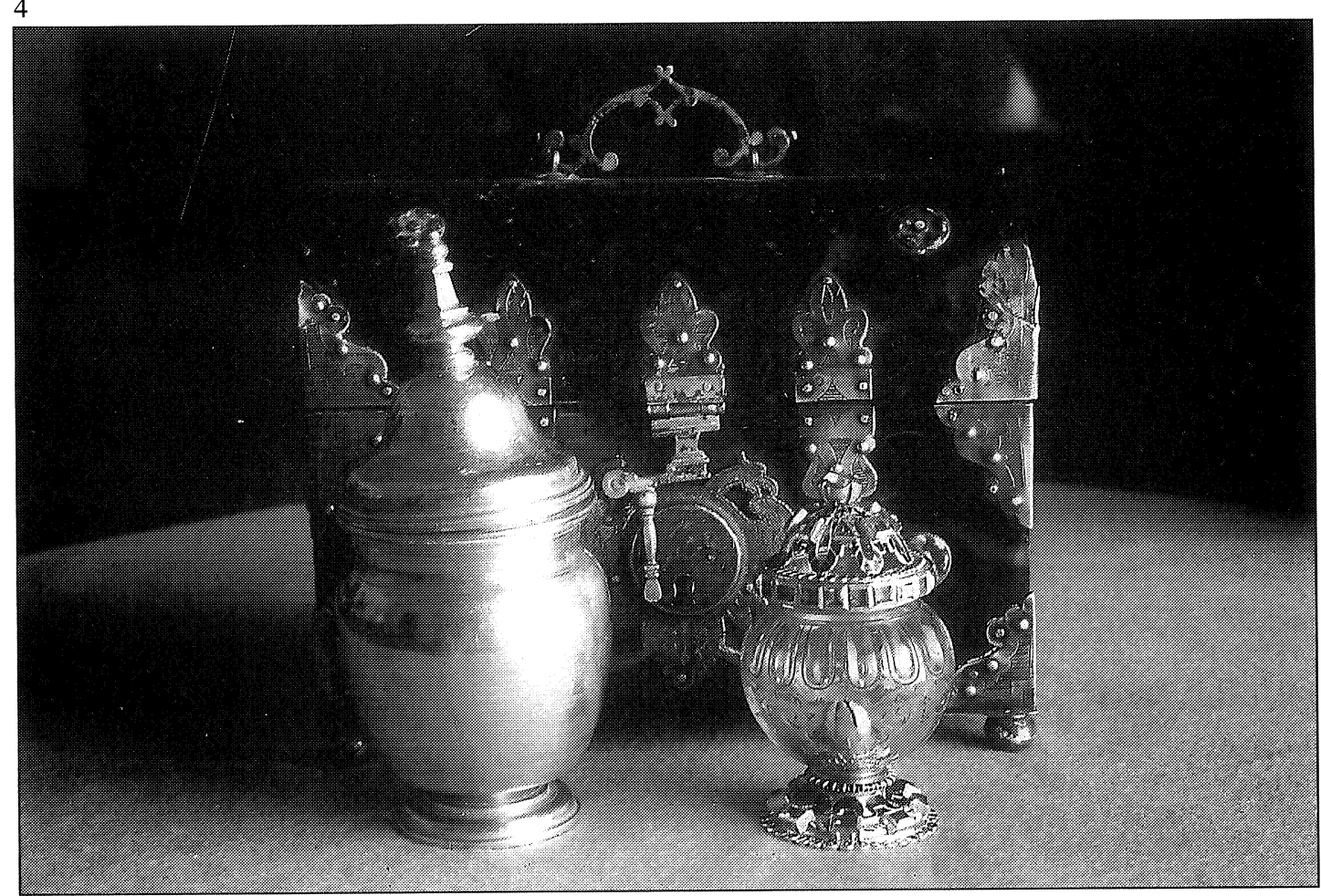

Fig. 3. Relicario de oro, cristal de roca, piedras y esmalte; procedente de Charcas, primeros años del siglo xviII. Fig. 4. Conjunto del relicario, estuche (plata sobredorada) y cofre (carey y plata).

$A E A$, LXXVII, 2004, 307, pp. 281 a 290 
para para el altar mayor, dos arañas para colgar delante de Nuestra Señora del Valle, dos ciriales, seis candeleros, dos juegos de vinajeras, un juego de incensario y naveta, y un portaviáticos. Por otro lado, en el inventario de 1798 se aprecia la ausencia de las sacras, de probable procedencia peruana, y las dos arañas. El resto de las alhajas vuelven a ser inventariadas, con aumento de tres cálices, una cruz de altar, seis candeleros de altar, una bandeja para poner los bonetes y cuatro coronas para distintas imágenes, que corresponderían a la producción de los talleres locales, probablemente ovetenses.

Fernando Ignacio Arango, aparte de dotar de alhajas a su colegiata, donó una lámpara y candeleros a la iglesia de San Andrés, parroquia de Pravia. Un documento datado en $1772^{33}$ habla de la idea de grabar una inscripción para que constara el nombre del Ilustrísimo Señor Obispo de Tuy por haber dado la lámpara y los candeleros. Otro documento datado en $1773^{34}$, atestigua la donación de Fernando Ignacio Arango de dos lámparas, una para el Santísimo Sacramento y otra para Nuestra Señora del Rosario en la iglesia de San Andrés, y una cruz, varios ciriales, un incensario y una naveta para la cofradía de las Ánimas, fundada en la misma iglesia. También donó a la parroquia un cofre de plata para custodiar la sagrada forma en el Jueves Santo, que pesaba 45 onzas y media $(1.308 \mathrm{~g})^{35}$. A través de dichas donaciones, se observa la atención y cuidado que el fundador de la colegiata de Pravia tenía hacia la iglesia parroquial, motivada por la propia devoción, y quizá para evitar envidias hacia la nueva obra fundada por él, que, aun siendo vice-parroquia, superaba con creces las dimensiones del templo parroquial.

${ }^{33}$ Martínez González, J. A., Apuntes para la historia de Pravia, [s/1], Solar Ediciones, 2000, pp. 120-121.

${ }^{34}$ Ibidem.

${ }^{35}$ En 1798 fundieron el cofre donado por Fernando Ignacio Arango para sufragar los gastos de una cruz y seis candeleros de plata para la parroquia. Archivo de la parroquia de Pravia, Libro de cuentas de la fábrica, año 1798, cargo. 